\title{
ADSORPTION OF CERTAIN TEXTILE DYES ONTO CHITOSAN. SPECTROSCOPIC AND THERMAL ANALYSIS
}

\author{
VIORICA DULMAN, ${ }^{*}$ GABRIELA LISA, ${ }^{* *}$ ELENA BOBU $^{* *}$ and DOINA ASANDEI ${ }^{* *}$ \\ *Alexandru Ioan Cuza University, Department of Organic Chemistry, Iasi, Romania \\ *Gheorghe Asachi Technical University of Iasi, 73, Prof. D. Mangeron Str., Iasi 700050, Romania \\ Corresponding author: D. Asandei, doinacazan@yahoo.com
}

Received February 7, 2019

\begin{abstract}
The characteristics of products obtained by adsorption of commercial dyes Bezanyl Green F2B (W), Procion Red MX5B (R), Procion Blue MX-R (D) onto chitosan were investigated by thermogravimetric analysis, FT-IR spectroscopy and polarized optical microscopy. The thermal degradation of pristine chitosan $(\mathrm{CH})$ and chitosan treated with dyes (CH-W, CH-R, CH-D) exhibited two decomposition stages, with a similar shape of the curves. Significant differences between the thermal parameters of the samples occurred during the second decomposition stage, and were correlated with the different structures of the dyes adsorbed onto $\mathrm{CH}$. The thermotropic behaviour of the samples investigated by polarized optical microscopy confirmed the data obtained from TGA.
\end{abstract}

Keywords: chitosan, acid dye, reactive dye, FTIR spectroscopy, thermal analysis, polarized optical microscopy

\section{INTRODUCTION}

The removal of acid and reactive dyes from wastewaters is of great importance since they tend to remain in the medium during conventional treatments. ${ }^{1,2}$ To solve this issue, many products have been used as dye adsorbents, those originating from renewable waste materials being especially attractive. The rapid development of this research direction indicated the biosorption as a pathway with real potential to replace conventional methods for the removal of textile dyes from wastewaters. ${ }^{3,4}$ Among the biopolymers used for this purpose, chitosan provided efficiency in dye removal. ${ }^{5-7}$ This is of great importance taking into consideration that chitosan is an excellent biomaterial, on the one hand, due to its abundance in nature and, on the other hand, due to its characteristics: biocompatibility, biodegradability, chemical stability, chelation ability, potential to develop physical and chemical bonds and thus to selectively retain different chemical species.

The results reported in the literature point out that the control of dye adsorption performance of a chitosan-based material depends on many factors, especially related to the two participants in the adsorption process, namely the chitosan and the dye.
The physicochemical characteristics of chitosan used as adsorbent in different forms (films, hydrogels, nanoparticles and composites) ${ }^{8-}$ 16 must be considered carefully during the optimization of the adsorption process. For a given type of chitosan, at optimal $\mathrm{pH}$ of the solution, the difference in the degree of adsorption may be attributed to the dye characteristics: molecular size, chemical structure, number and position of the sulfonate groups, content of pure dye and of additives in the commercial dye products or different substances added during the dying process. The monovalent and smaller dyes are reported to have superior adsorption capacities due to an increased dye/chitosan ratio in the system, which enables deeper penetration of the dye molecules into the internal pore structure of the chitosan. ${ }^{5,7}$ On the contrary, in the case of some acid dyes, it was found that large dye molecules and trivalent dye ions result in lower adsorption capacity values. ${ }^{17}$ The elucidation of the adsorption mechanism of dyes onto chitosan may help to optimize the bioadsorption process. For example, it was established that the adsorption capacity of some acid and reactive dyes onto chitosan is clearly influenced by $\mathrm{pH}$, dye concentrations, contact 
time, temperature and concentration of the added sodium chloride. ${ }^{18-20}$

A few studies on the thermal degradation of adsorbents based on chitosan demonstrated that the thermogravimetric technique brings important information related to the intermolecular forces between chitosan and dyes. ${ }^{21-26}$ They showed that the profile of the TG/DTG curves consists in the presence of two peaks corresponding to the two mass loss steps. The first, from 25 to $220{ }^{\circ} \mathrm{C}$, is attributed to the loss of water, which is adsorbed both on the surface and in the pores of chitosan. The second step, from 220 to $420^{\circ} \mathrm{C}$, corresponds to the decomposition of the chitosan structure.

In this paper, the thermal stability, degradation and adsorption characteristics of pristine chitosan and three chitosan-dye products, obtained by dye adsorption from aqueous solutions under the optimal conditions onto chitosan, were investigated. The dyes used in this study were Bezanyl Green F2B (a triphenylmethane acid dye), Procion Red MX-5B (an anthraquinone reactive dye) and Procion Blue MX-R (an azo reactive dye). The main objective of this study was to provide an insight into the mechanism of dye adsorption, by monitoring data provided by FT-IR spectroscopy, TG-DTG analysis, and

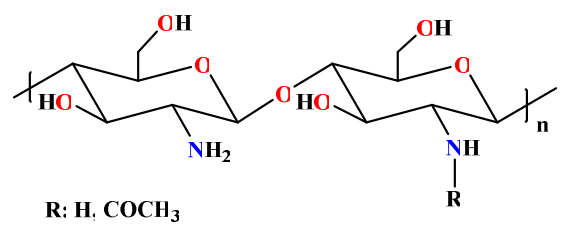

Chitosan (CH) $\mathrm{M}_{\mathrm{W}}: 415000 \mathrm{~g} / \mathrm{mol}$

(a)

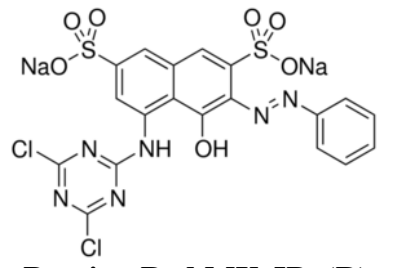

Procion Red MX-5B (R)

$\mathrm{C}_{19} \mathrm{H}_{10} \mathrm{Cl}_{2} \mathrm{~N}_{6} \mathrm{Na}_{2} \mathrm{O}_{7} \mathrm{~S}_{2} ; \mathrm{M}_{\mathrm{W}}: 615.34 \mathrm{~g} / \mathrm{mol}$

(c) polarized light optical microscopy (POM). These results allowed comparing the chitosan affinity for the three dyes from the point of view of structural features of the adsorbed dyes. To the best of our knowledge, no data on this subject regarding the investigated products has been reported so far in the literature.

\section{EXPERIMENTAL}

\section{Materials}

Chitosan powder, with particle size $<200 \mu \mathrm{m}$, acetylation degree of $20.8 \%$, loss on drying of $4.5 \%$ and a relative molecular weight mass of $415000 \mathrm{~g} / \mathrm{mol}$, was purchased from Vanson Co., Canada. Bezanyl Green F2B (C.I.-42100, Acid Green 9), 72\%, and Procion Red MX-5B (C.I.-18200 Reactive Red 2), $85 \%$, were provided from the Faculty of Textiles and Leather, Iasi (Romania). Procion Blue MX-R (C.I.1205 Reactive Blue 4), 35\%, was purchased from Sigma-Aldrich. The dyes were used without further purification, considering only the dye content in the commercial product in the experimental calculations. The chemical structure and the characteristics of the chitosan and the investigated dyes are shown in Scheme 1.

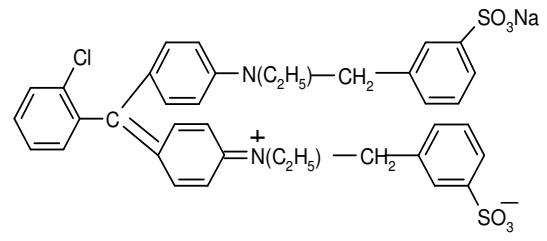

Benzanyl Green F2B (W)

$\mathrm{C}_{37} \mathrm{H}_{34} \mathrm{ClN}_{2} \mathrm{NaO}_{6} \mathrm{~S}_{2} ; \mathrm{M}_{\mathrm{W}}: 724.5 \mathrm{~g} / \mathrm{mol}$

(b)

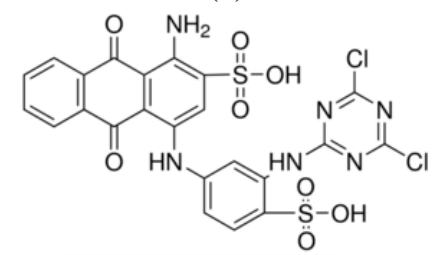

Procion Blue MX-R (D)

$\mathrm{C}_{23} \mathrm{H}_{14} \mathrm{Cl}_{2} \mathrm{~N}_{6} \mathrm{O}_{8} \mathrm{~S}_{2} ; \mathrm{M}_{\mathrm{W}}: 637.43 \mathrm{~g} / \mathrm{mol}$

(d)

Scheme 1: Structure of (a) chitosan and dyes: (b) Benzanyl Green F2B (W); (c) Procion Red MX-5B (R); and (d) Procion Blue MX-R (D)

\section{Preparation of the samples}

An amount of $0.3 \mathrm{~g}$ of chitosan powder was added to $200 \mathrm{~mL}$ of dye solution, with an optimum concentration and $\mathrm{pH}$, previously established as follows: $200 \mathrm{mgL}^{-1}, \mathrm{pH}=5.5$ for Benzanyl Green F2B (W); $80 \mathrm{mgL}^{-1}, \mathrm{pH}=8$ for Procion Red MX-5B (R), and $250 \mathrm{mgL}^{-1}, \mathrm{pH}=8$ for Procion Blue MX-R (D). The mixtures were constantly mechanically stirred until the 
adsorption equilibrium was attained: 6 hours in the case of $\mathrm{W}$ dye, 4 hours for $\mathrm{R}$ dye and 1 hour for $\mathrm{D}$ dye. The obtained products were separated from the solution by filtration and then dried at room temperature $\left(20^{\circ} \mathrm{C}\right)$. The amount of dye adsorbed onto chitosan was established by spectrophotometrical determination of the dye concentration remaining in the solution at the maximum absorbance wavelength of each dye $\left(\lambda_{\max }=643 \mathrm{~nm}\right.$ for $\mathrm{W} ; \lambda_{\max }=538 \mathrm{~nm}$ for R; $\lambda_{\max }=595 \mathrm{~nm}$ for D). D dye was the best retained in the CH-D product: $0.366 \mathrm{mmol} / \mathrm{g} \sim 23 \%$ of the sample mass; $\mathrm{R}$ dye was less retained in the $\mathrm{CH}-\mathrm{R}$ product: $0.184 \mathrm{mmol} / \mathrm{g} \sim 11 \%$ of the sample mass; W was the least retained in $\mathrm{CH}-\mathrm{W}: 0.138 \mathrm{mmol} / \mathrm{g} \sim 10 \%$ of the sample mass.

\section{Methods}

FT-IR spectra were recorded on a Bio-Rad DIGILAB FTS 2000 Spectrophotometer, in the transmission mode, on $\mathrm{KBr}$ pellets obtained from chitosan before and after dye adsorption. Similar amounts of samples were used. The transmittance spectra were recorded over the $400-4000 \mathrm{~cm}^{-1}$ domain, and subsequently normalized to unity.

Thermal tests were conducted using a Mettler Toledo derivatograph under nitrogen atmosphere, at 20 $\mathrm{mL} / \mathrm{min}$ flow and $15{ }^{\circ} \mathrm{C} / \mathrm{min}$ rate of heating, within the temperature range from 25 to $800{ }^{\circ} \mathrm{C}$. The samples weighed 3-4 mg. In order to get comparable data, the operation parameters were kept constant for all the samples. Curve processing, designed to determine the thermal and kinetic characteristics, was performed using the STAR software developed by Mettler Toledo.

The thermotropic behaviour of the samples was investigated by polarized light optical microscopy (POM) with an Olympus $\mathrm{BH}-2$ polarized light microscope under cross polarizers, equipped with a THMS 600/HSF9I hot stage and a LINKAM TP92 temperature control system. The measurements were performed on $1 \mathrm{mg}$ of sample, which was placed between two glass lamella.

\section{RESULTS AND DISCUSSION \\ Adsorption mechanism. Premises}

Generally speaking, the mechanism of dye removal from acidic or alkaline solutions by chitosan is complex and includes both physical and chemical adsorption, but their involvement depends on the dye-chitosan system peculiarities. The chitosan used in this study has an acetylation degree of $20.8 \%$, meaning that the amino $\left(-\mathrm{NH}_{2}\right)$, hydroxyl $(-\mathrm{OH})$ and acetamide $\left(\mathrm{CH}_{3}-\mathrm{CONH}-\right)$ groups could serve as reactive sites. The accessible amine groups in chitosan are the main reactive groups for anionic dye adsorption, although the hydroxyl groups (especially in the C3 position) may also contribute to this process. ${ }^{5}$

On the other hand, the structure and characteristics of the investigated dyes are different, as described below.

For triphenylmethane acid dye $\mathrm{W}$, it could be assumed that, at the optimum $\mathrm{pH}$ value of 5.5, it undergoes partial protonation (weakly acidic solution) of the nitrogen atoms, which favours the adsorption the dye anion by the ion exchange process, according to the general equilibrium.It may be mentioned that in an acidic solution, interactions between the acetamide groups $\left(\mathrm{CH}_{3}\right.$ CONH-) of the chitosan and the dye can take place. It is known that at low $\mathrm{pH}$ values, $\mathrm{H}_{3} \mathrm{O}^{+}$ ions react to a significant extent with the amide groups -CO- $\mathrm{NH}_{2}-{ }^{5,15}$ It should, however, be noted that these groups exist in a small proportion in the chitosan and have a much smaller affinity for the hydronium ion than the primary amine groups.

The dye molecules adsorbed onto chitosan are more or less attached to adsorbent molecules in a flat or layered manner, that is, covering the chitosan backbones with benzene rings parallel oriented (as far as possible) to the polysaccharide chain of chitosan. If the attachment of the dye occurs at one site only (electrostatic reaction between amino and sulfonate groups), it would be expected that the dye molecules should be spatially oriented in a more perpendicular manner. Beside the electrostatic attraction forces, hydrogen bonds can also play an important role in the adsorption process, since the dye also has many nitrogen and chlorine electronegative atoms, which can form $\mathrm{H}$ bonds with the $\mathrm{OH}$ units of chitosan. Moreover, van der Waals forces should be also considered. ${ }^{26-28}$

Related to the theoretical premises of the adsorption mechanism of the Procion Red MX-5B and Procion Blue MX-R dyes in a weakly alkaline solution $(\mathrm{pH}=8)$, studies on the absorption of reactive dyes onto cellulose fibres, under similar basic conditions, demonstrated the preferential reaction of the primary hydroxyl groups of the cellulose. $^{29,30}$ As the chitosan biopolymer is chemically similar to cellulose (except the primary aliphatic amino group at the carbon 2), a similar adsorption mechanism of the reactive dyes onto chitosan at alkaline $\mathrm{pH}$ can be envisaged. It may be hypothesised that the hydroxyl group of the chitosan could covalently bond the reactive dyes, but the possibility of reaction of the amine groups should not be neglected, taking into consideration their better reactivity to anionic 
dyes. ${ }^{15}$ Thus, for the adsorption of anthraquinone reactive dye Procion Red MX-5B and azo reactive dye Procion Blue MX-R onto chitosan at $\mathrm{pH}=8$, a possible covalent bonding of the reactive dyes at amine and hydroxyl groups can be considered. ${ }^{18}$

\section{Structural characterization by FTIR spectroscopy}

To establish the mechanism of retention of the dyes on chitosan, the structure of the chitosandye products was investigated by FTIR spectroscopy and compared with the chitosan reference (Fig. 1). As expected, the FTIR spectrum of $\mathrm{CH}$ reveals the main vibration bands of its covalent linkages and also the hydrogen bonds formed due to the presence of the hydroxyl and amine groups. Thus, in the $3700-2700 \mathrm{~cm}^{-1}$ spectral domain, a broad band with the absorption maximum at $3440 \mathrm{~cm}^{-1}$ appears and is attributed to the occurrence of stretching vibrations of the hydroxyl and amine groups involved in both intraand inter-molecular hydrogen bonds, formed among the $\mathrm{OH}$ groups (primary or secondary), furanosic $\mathrm{O}$ atoms, and $\mathrm{NH}$ units. ${ }^{26}$ The broad band originates from the overlapped bands of the vibrations of these bonds, with two evident principal maxima located at 3440 and $3245 \mathrm{~cm}^{-1}$. In the FTIR spectra of the $\mathrm{CH}-\mathrm{W}$ sample, these two maxima are shifted, the first to a higher wavelength, $3450 \mathrm{~cm}^{-1}$, and the second to a lower wavelength, $3218 \mathrm{~cm}^{-1}$, respectively, indicating significant changes of the H-bonding environment, consisting mainly in the weakening of the intramolecular forces and strengthening of the intermolecular ones. This is in agreement with the formation of new H-bonds between chitosan and the acidic $\mathrm{W}$ dye. ${ }^{31}$ In the case of the CH-D and CH-R samples, the shifting to higher or lower wavelength was less evident, to 3445 and 3239 $\mathrm{cm}^{-1}$, respectively, suggesting a slighter implication of these bonds during the dye adsorption process. This could be related to the well-known aspect that the weak alkaline aqueous solutions of reactive dyes become unreactive towards the substrate with - $\mathrm{OH}$ groups through hydrolysis. ${ }^{32}$

The shifting of the band to higher wavenumbers could also reflect the diminishing of the $\mathrm{NH}$ groups available for $\mathrm{H}$ bond formation, in agreement with the involvement of these groups in the formation of new bonds with the dyes, as stated above.

Concerning the other absorption bands of chitosan: $1650 \mathrm{~cm}^{-1}$ (-NH stretching vibration), $1380 \mathrm{~cm}^{-1}$ (- $\mathrm{CH}_{2}$ deformation), $1150 \mathrm{~cm}^{-1}$ (C=O stretching), 1085 (O-H stretching) and $617 \mathrm{~cm}^{-1}$ ( $\mathrm{OH}$ bending), no significant shifting was observed after dye absorption, which mainly indicates the physical adsorption of the dyes onto chitosan. ${ }^{33}$ On the other hand, comparing the intensity of the $-\mathrm{NH}$ stretching vibration (1650 $\mathrm{cm}^{-1}$ ) for the three chitosan-dye samples, its decline was noted in the case of the CH-D sample, suggesting a better ability of the $-\mathrm{NH}$ in the acetamide groups of chitosan to develop physical interactions with the $\mathrm{D}$ dye, most probably due to the presence of the $\mathrm{C}=\mathrm{O}$ groups, via $-\mathrm{NH} \ldots \mathrm{O}=\mathrm{C}$ hydrogen bonds. No clear absorption bands of the $\mathrm{C}=\mathrm{C}$ linkage of the aromatic ring of the dyes $\left(1500\right.$ and $\left.1600 \mathrm{~cm}^{-1}\right)$ were noted in the spectra, most probably because they overlapped with the absorption bands of chitosan.

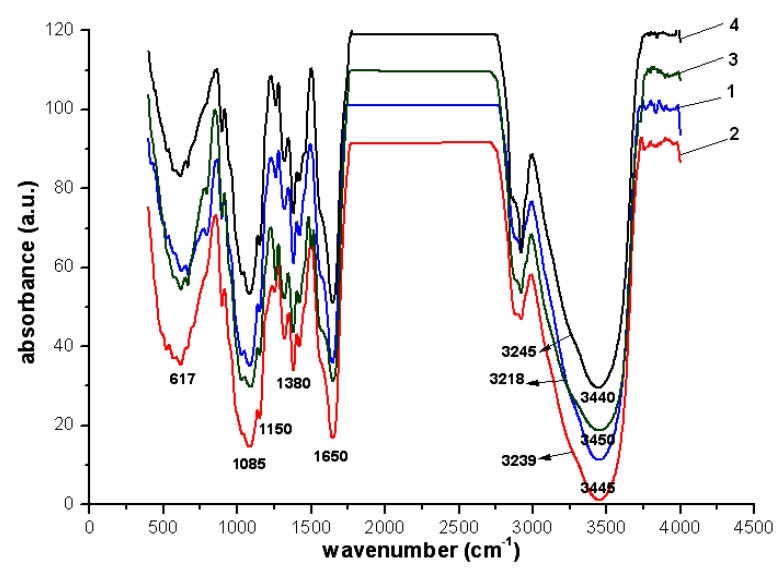

Figure 1: FTIR spectra of chitosan and chitosan-dye samples: 1- CH-D, 2-CH-R, 3-CH-W, 4-CH 

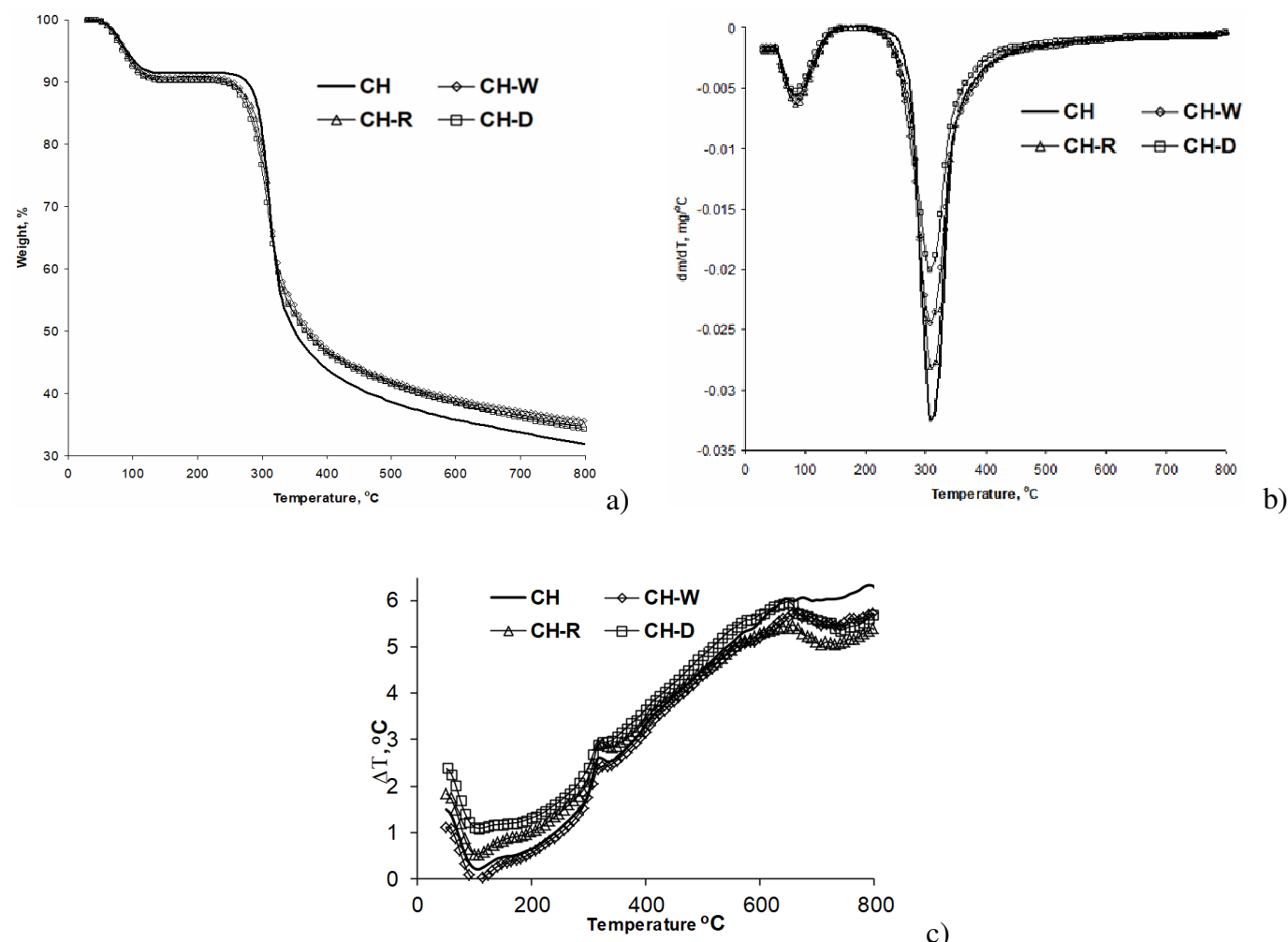

c)

Figure 2: TG (a), DTG (b) and DTA (c) curves of chitosan and chitosan-dye samples

Table 1

Thermogravimetric characteristics

\begin{tabular}{|c|c|c|c|c|c|c|c|}
\hline Sample & Stage & $\mathrm{T}_{\text {onset }}$ & $\mathrm{T}_{\text {peak }}$ & $\mathrm{T}_{\text {endset }}$ & $\mathrm{W} \%$ & $\begin{array}{c}\text { DTA } \\
\text { characteristic }\end{array}$ & $\begin{array}{l}\text { Residue } \\
\text { at } 800^{\circ} \mathrm{C}\end{array}$ \\
\hline \multirow{2}{*}{$\mathrm{CH}$} & I & 58 & 86 & 115 & 8.53 & endo & \multirow{2}{*}{31.31} \\
\hline & II & 288 & 311 & 378 & 60.16 & exo & \\
\hline \multirow{2}{*}{$\mathrm{CH}-\mathrm{W}$} & I & 54 & 86 & 119 & 9.18 & endo & \multirow{2}{*}{35.10} \\
\hline & II & 264 & 309 & 421 & 55.72 & exo & \\
\hline \multirow{2}{*}{$\mathrm{CH}-\mathrm{R}$} & I & 58 & 86 & 117 & 9.64 & endo & \multirow{2}{*}{34.56} \\
\hline & II & 279 & 311 & 414 & 55.80 & exo & \\
\hline \multirow{2}{*}{ CH-D } & I & 59 & 82 & 119 & 9.74 & endo & \multirow{2}{*}{33.36} \\
\hline & II & 260 & 309 & 411 & 56.90 & exo & \\
\hline
\end{tabular}

The investigation of the adsorption behaviour of some reactive dyes containing the dichlorotriazine group onto cellulose revealed that at basic $\mathrm{pH}$, a covalent bond formed between a triazine carbon atom and an oxygen atom. ${ }^{34}$

In a similar way, for $\mathrm{R}$ and $\mathrm{D}$ triazine containing dyes, covalent bond formation could be also expected. This is quite difficult to identify by FTIR spectroscopy, as the vibration band of the ether and hydroxyl groups of the chitosan superposed with the newly ether bond supposed to be formed. Even so, a broader band in the case of the CH-R sample could be assigned to the formation of a percent of such linkages. No such widening was observed in the case of the CH-D sample, possibly because of the higher volume of the $\mathrm{D}$ dye, which hindered its access to the hydroxyl units of chitosan.

\section{Thermal analysis}

Figure 2 shows the thermogravimetric (TG), derivative thermogravimetric (DTG) and differential thermal analysis (DTA) curves recorded for the three chitosan-dye samples and 
the chitosan reference. As can be seen, the thermal degradation of the samples comprises two stages (Fig. 2a). Table 1 includes the main thermogravimetric characteristics, namely: $\mathrm{T}_{\text {onset }}-$ initial temperature at which the thermal degradation starts, $\mathrm{T}_{\text {peak }}-$ when the rate of degradation reaches its peak, $\mathrm{T}_{\text {endset }}-$ when the degradation process of each stage is completed, W\% - mass percentage losses occurring in each stage, DTA characteristics and amount of residue at $800{ }^{\circ} \mathrm{C}$. The first process occurring at temperatures below $120{ }^{\circ} \mathrm{C}$ is associated to humidity removal from the samples. The mass percentage loss in this stage amounts to about 8$10 \%$, this level being lower in the $\mathrm{CH}-\mathrm{W}, \mathrm{CH}-\mathrm{R}$ and $\mathrm{CH}-\mathrm{D}$ samples than in the $\mathrm{CH}$ control sample. The explanation is quite evident: the dyes obstructed the chitosan pores, which were less available for moisture. Moreover, the dyes increased the hydrophobicity of the chitosan surface, decreasing its affinity for water.

The comparative analysis of the thermal characteristics of the chitosan and the chitosandye samples revealed the maximum of degradation in the second stage at a similar temperature, i.e. $\cong 310{ }^{\circ} \mathrm{C}$. Literature data ${ }^{21-25}$ attributed the onset of the thermal decomposition of chitosan in inert atmosphere to the break of the C-O-C bonds, leading to depolymerization, with the formation of monomer and acetamide $\mathrm{C}_{2} \mathrm{H}_{5} \mathrm{NO}(\mathrm{m} / \mathrm{e}=59)$, respectively.

Significant differences between the thermal characteristics of the analysed samples occurred in $\mathrm{T}_{\text {onset }}$ temperature and mass percentage loss during the second stage. Therefore, the onset temperature of the thermal decomposition of the chitosan-dye samples was by 9 to $29{ }^{\circ} \mathrm{C}$ lower than the thermal decomposition onset temperature of the control chitosan. Also, the mass percentage loss in this stage was 3-4\% lower in the $\mathrm{CH}-\mathrm{W}$, CH-R and CH-D samples, compared to the chitosan sample. Similar results were reported by Vasconcelos for chitosan after adsorption of RO 16 dye, ${ }^{35}$ who considered that the adsorption of this dye onto chitosan produced a new material, less thermally stable. Considering the FTIR observations, we attribute this decrease of the $\mathrm{T}_{\text {onset }}$ temperature and mass percentage loss to the formation of inter-molecular $\mathrm{H}$-bonds between the chitosan and the dyes, which disturbed the intermolecular $\mathrm{H}$ bonds of chitosan, destroying thus the packing of chitosan chains and making it more susceptible to degradation. As the first stage was assigned to water removal, the $T_{\text {onset }}$ temperature in the second stage has been considered as a thermal stability criterion. In line with this, the thermal stability of the samples follows the following increasing trend: $\mathrm{CH}-\mathrm{D}<$ $\mathrm{CH}-\mathrm{W}<\mathrm{CH}-\mathrm{R}<\mathrm{CH}$. This thermal stability scale is in good agreement with the FTIR data, which indicated possible formation of stable covalent bonds between chitosan and the $\mathrm{R}$ dye, a higher amount of inter-molecular H-bonds between chitosan and the $\mathrm{W}$ dye, and a lower amount of $\mathrm{H}$ bonds between the acetamide $-\mathrm{NH}$ of chitosan and the $\mathrm{C}=\mathrm{O}$ of the $\mathrm{D}$ dye, which should be quantitatively less important considering the lower percent of amide groups on chitosan.

The data shown in Table 1 and Figure $2 \mathrm{a}$ also display larger amounts of residue at $800{ }^{\circ} \mathrm{C}$ in the $\mathrm{CH}-\mathrm{W}, \mathrm{CH}-\mathrm{R}$ and $\mathrm{CH}-\mathrm{D}$ samples, compared to the chitosan reference sample, which has been attributed to the more compact structure of the dyes entrapped into chitosan, which made it less susceptible to degradation.

In order to determine the activation energy, the pre-exponential factor and the order of reaction, the kinetic processing of thermogravimetric data has been realized, applying the Freeman-Carroll differential method, ${ }^{24}$ based on the following equation:

$\frac{\mathrm{d} \alpha}{\mathrm{dt}}=\mathrm{A} \cdot \mathrm{e}^{-\frac{\mathrm{E}_{\mathrm{a}}}{\mathrm{RT}}}(1-\alpha)^{\mathrm{n}}$

where $\mathrm{d} \alpha / \mathrm{dt}$ - variation of the transformation over time, A - pre-exponential factor, $\mathrm{E}_{\mathrm{a}}$ - activation energy in $\mathrm{J} \mathrm{mol}^{-1}, \mathrm{R}$ - universal gas constant = $8.31 \mathrm{~J} \mathrm{~mol}^{-1} \mathrm{~K}^{-1}, \mathrm{~T}$ - temperature in the sample in $\mathrm{K}, \alpha$ - transformation degree and $\mathrm{n}$ - order of reaction.

In order to obtain comparable data, the values of the kinetic parameters were calculated for the same temperature interval $\left(280-320{ }^{\circ} \mathrm{C}\right)$, that is transformation degrees between 0.15 and 0.55 , for all the analysed samples. We found values of the order of reaction between 1.2 and 1.9, and lower values of the activation energy of the samples containing dyes, as compared to that of the control sample. When comparing the activation energy values, we find the same thermal stability sequence as determined previously based on the thermal characteristics: $\mathrm{CH}-\mathrm{D}<\mathrm{CH}-\mathrm{W}<\mathrm{CH}-\mathrm{R}<$ $\mathrm{CH}$.

An interpretation of the activation energy data suggests the following. (i) The D dye, which was retained onto chitosan in the highest amount (0.366 $\mathrm{mmol} / \mathrm{g} \sim 23 \%$ of the sample mass) 
induced a reduction of the thermal stability of about $50 \%(\mathrm{Ea}=155.87 \pm 2.53 \mathrm{~kJ} / \mathrm{mol})$, compared to the control $(\mathrm{Ea}=314.48 \pm 1.83 \mathrm{~kJ} / \mathrm{mol})$. This behaviour is in agreement with the presence of a low amount of labile H-bonds between the chitosan and the dye. (ii) Although the affinity of chitosan for azo reactive dye $\mathrm{R}$ was lower $(0.184$ $\mathrm{mmol} / \mathrm{g} \sim 11 \%$ of the sample mass), the $\mathrm{CH}-\mathrm{R}$ product was more thermally stable $(\mathrm{Ea}=$ 255.27 \pm 3.03$)$ than the CH-D sample and less stable than the $\mathrm{CH}$ sample (Ea value decreases by $\sim 19 \%$ ).

Table 2

Kinetic parameters in the second stage

\begin{tabular}{lccc}
\hline Sample & $\mathrm{n}$ & $\begin{array}{c}\mathrm{Ea} \\
(\mathrm{kJ} / \mathrm{mol})\end{array}$ & $\ln \mathrm{A}$ \\
\hline $\mathrm{CH}$ & $1.87 \pm 0.003$ & $314.48 \pm 1.83$ & $61.15 \pm 0.39$ \\
$\mathrm{CH}-\mathrm{W}$ & $1.38 \pm 0.002$ & $199.06 \pm 2.94$ & $36.93 \pm 0.63$ \\
CH-R & $1.52 \pm 0.002$ & $255.27 \pm 3.03$ & $48.63 \pm 0.65$ \\
CH-D & $1.22 \pm 0.003$ & $155.87 \pm 2.53$ & $27.82 \pm 0.55$ \\
\hline
\end{tabular}

It is evident that the interaction between chitosan and the D dye is weaker than in the CH-R sample. Comparing the thermal behaviour of the two products containing reactive dyes with different chromophore core, this was attributed to a physical mechanism of adsorption for the $\mathrm{D}$ dye and a prevalent chemical mechanism for the $R$ dye.

The product $\mathrm{CH}-\mathrm{W}, \quad$ containing triphenylmethane acid dye $\mathrm{W}$, occupies an intermediate position (a reduction of $\mathrm{Ea} \sim 37 \%$ ), although the content of the dye is the smallest $(0.138 \mathrm{mmol} / \mathrm{g} \sim 10 \%$ of the sample mass $)$. This has been assigned to the higher amount of intermolecular $\mathrm{H}$-bonds and possible ionic linkages between the chitosan and the dye.

Overall, the thermal stability of the chitosandye samples shows the key role played by the intermolecular forces developed between the two components, which is dependent not only on the maximum amount of dye adsorbed, but, to a large extent, on the chemical structure of each dye.

\section{Polarized light optical microscopy}

Polarized optical microscopy is a powerful tool, especially useful in the characterization of supramolecular structures ${ }^{34}$ in homogeneous or heterogeneous mixtures. The observation of the chitosan sample at room temperature revealed white crystals, with birefringent transparency at their thin borders. By comparison, the chitosandye samples, CH-D, CH-W, CH-R, showed coloured crystals in all the cases, keeping the colour of the encapsulated dye (Fig. 3 a, b, c, d). The crystals were uniformly coloured and they maintained the birefringent transparency at the border, indicating a very fine distribution of the dye molecules in the chitosan pores, most probably as monolayers, as the Langmuir model suggested. ${ }^{18}$ Moreover, the crystals present clear birefringence into the bulk as well, with an oily streak texture characteristic of a layered architecture, suggesting that the dye molecules are diffused between the plains of chitosan chains.

During the heating of the chitosan and chitosan-dye samples, no visible modifications have been seen up to $250{ }^{\circ} \mathrm{C}$, confirming that no degradation process takes place and, consequently, the first TG peak belongs to water loss. At higher temperatures, the crystals darkened, indicating the onset of thermal degradation. The colour of the crystals changed slowly in the temperature range of about $30-40{ }^{\circ} \mathrm{C}$ (Fig. 3 e, f, g, h). Interesting enough, while the chitosan became almost brown at $250{ }^{\circ} \mathrm{C}$, the other dye containing samples darkened at higher temperatures (see Fig. 3 e, f, g, h). This indicates that the decomposition of the chitosan-dye samples started with the disruption of the physical forces between the chitosan chains and the dye molecules, when the temperature increased and the dye escaped from the superficial layers of chitosan by sublimation. 


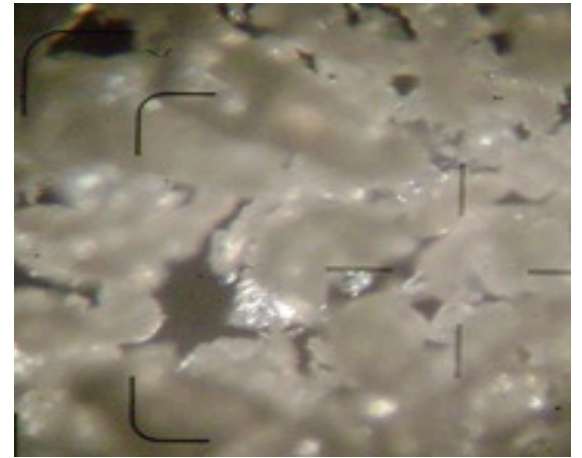

a) $\mathrm{CH}, \mathrm{RT}$

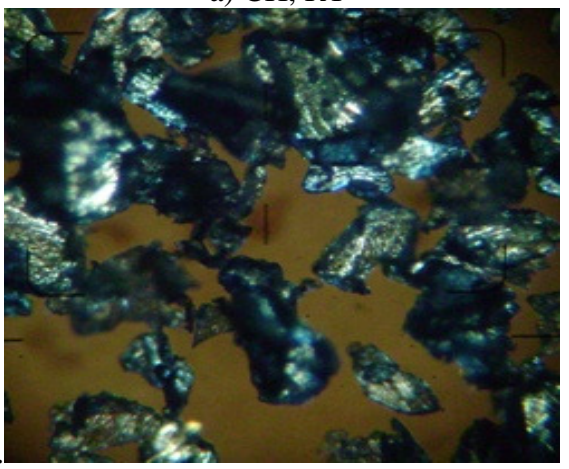

b) $\mathrm{CH}-\mathrm{D}, \mathrm{RT}$

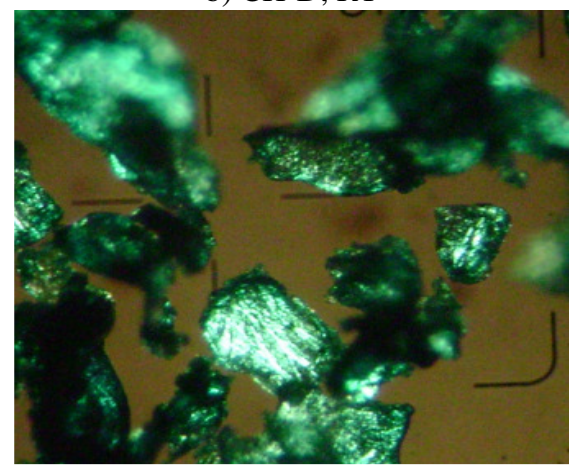

c) $\mathrm{CH}-\mathrm{W}, \mathrm{RT}$

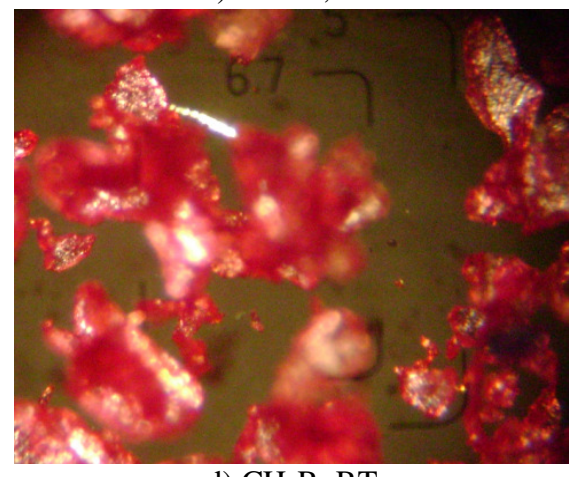

d) $\mathrm{CH}-\mathrm{R}, \mathrm{RT}$

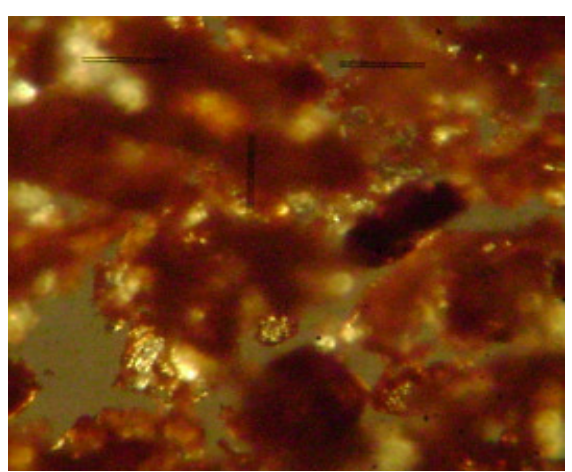

e) $\mathrm{CH}, 250^{\circ} \mathrm{C}$

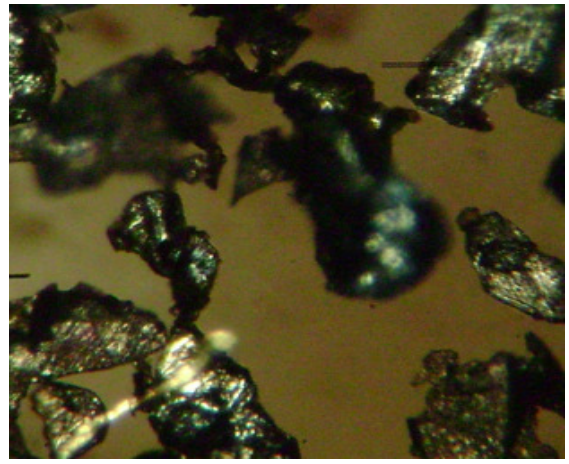

f) $\mathrm{CH}-\mathrm{D}, 270^{\circ} \mathrm{C}$

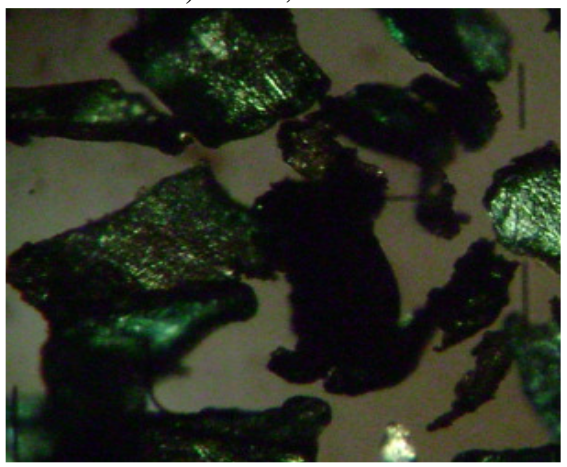

g) $\mathrm{CH}-\mathrm{W}, 260^{\circ} \mathrm{C}$

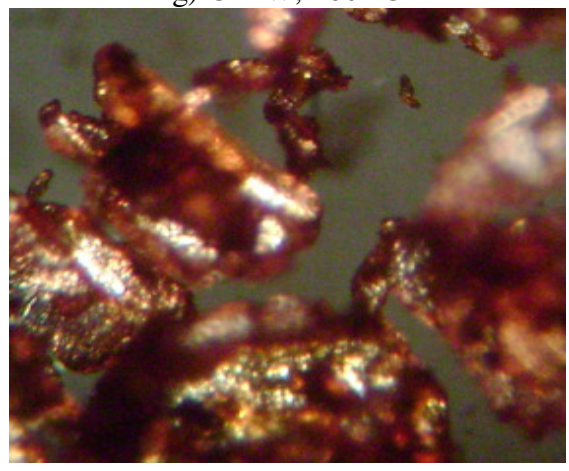

h) $\mathrm{CH}-\mathrm{R}, 290^{\circ} \mathrm{C}$

Figure 3: POM images of a) $\mathrm{CH}$, b) $\mathrm{CH}-\mathrm{D}$, c) $\mathrm{CH}-\mathrm{W}$, d) $\mathrm{CH}-\mathrm{R}$ at room temperature (RT), and of e) $\mathrm{CH}, \mathrm{f}) \mathrm{CH}-\mathrm{D}$, g) $\mathrm{CH}-\mathrm{W}, \mathrm{h}) \mathrm{CH}-\mathrm{R}$ at the temperature corresponding to visible darkening; (all the images were acquired at a magnification of $10 \times 10)$ 


\section{CONCLUSION}

The adsorption of three different textile dyes, Bezanyl Green F2B (W), Reactive Red 2 (R) and Reactive Blue 4 (D), onto chitosan was studied by FTIR spectroscopy and thermal methods.

The FTIR spectra indicated that the adsorption process took place preponderantly by physical interactions for the $\mathrm{W}$ and $\mathrm{D}$ dyes, and by chemical and physical bonds in the case of the $\mathrm{R}$ dye. This hypothesis has been supported by the TG-DTG analysis, which clearly showed the variation of the thermal parameters according to the intermolecular forces evidenced by FTIR spectroscopy. Thus, it was established that the W and $\mathrm{D}$ dyes developed mainly physical forces towards the chitosan chains, being preponderantly physically adsorbed into the chitosan pores. On the other hand, the $\mathrm{R}$ dye was bonded to the chitosan via covalent bonds, being retained on chitosan by prevalently chemical adsorption. Moreover, the polarized light microscopy analysis indicated that the adsorption of the dyes occurred most probably in monolayers.

\section{REFERENCES}

1 V. K. Gupta and Suhas, J. Environ. Manage., 90, 2313 (2009),

https://doi.org/10.1016/j.jenvman.2008.11.017

2 Y. Zhou, J. Lu, Y. Zhou and Y. Liu, Environ. Pollut., 252, $352 \quad$ (2019), https://doi.org/10.1016/j.envpol.2019.05.072

3 Z. Aksu, Process. Biochem., 40, 997 (2005), https://doi.org/10.1016/j.procbio.2004.04.008

4 G. Crini, Bioresour. Technol., 97, 1061 (2006), https://doi.org/10.1016/j.biortech.2005.05.001

5 G. Crini and P.-M. Badot, Prog. Polym. Sci., 33, 399 (2008), https://doi.org/10.1016/j.progpolymsci.2007.11.001

6 P. M. Pakdel and S. J. Peighambardoust, Carbohyd. Polym., 201, 264 (2018), https://doi.org/10.1016/j.carbpol.2018.08.070

7 M. Vakili, S. Deng, L. Shen, D. Shan, D. Liu et al., Sep. Purif. Rev., 48, 1 (2019), https://doi.org/10.1080/15422119.2017.1406860

8 S. Yu, J. Cui, H. Jiang, C. Zhong and J. Meng, Int. J. Biol. Macromol., 134, 830 (2019), https://doi.org/10.1016/j.ijbiomac.2019.04.208

9 J. Xing, X. Wang, J. Xun, J. Peng, Q. Xu et al., Carbohyd. Polym., 198, $69 \quad$ (2018), https://doi.org/10.1016/j.carbpol.2018.06.064

10 A. Shajahan, S. Shankar, A. Sathiyaseelan, K. S. Narayan, V. Narayanan et al., Int. J. Biol. Macromol., 104 1449

https://doi.org/10.1016/j.ijbiomac.2017.05.128
11 S. Kumar, B. Krishnakumar, A. J. F. N. Sobral and J. Koh, Carbohyd. Polym., 205, 559 (2019), https://doi.org/10.1016/j.carbpol.2018.10.108

12 B. Chen, H. Zhao, S. Chen, F. Long, B. Huang et al., Chem. Eng. J., 356, 69 (2019), https://doi.org/10.1016/j.cej.2018.08.222

13 B. Tanhaei, A. Ayati and M. Sillanpaa, Int. J. Biol. Macromol., $\quad$ 121, $1126 \quad$ (2019), https://doi.org/10.1016/j.ijbiomac.2018.10.137

14 A. Ibanescu, M. C. Alexandrica, D. Hritcu, O. Chiscan and M. I. Popa, Green Mater., 6, 149 (2018), https://doi.org/10.1680/jgrma.18.00039

15 X.-Y. Huang, X.-Y. Mao, H.-T. Bu, X.-Y. Yu, G.B. Jiang et al., Carbohyd. Res., 346, 1232 (2011), https://doi.org/10.1016/j.carres.2011.04.012

16 H. Ansari, M. Miralinaghi and F. Azizinezhad, Cellulose Chem. Technol., 53, 191 (2019), https://doi.org/10.35812/CelluloseChemTechnol.2019. 53.20

17 A. R. Cestari, E. F. S. Vieira, A. G. P. dos Santos, J. A. Mota and V. P. de Almeida, J. Colloid. Interf. Sci., 280, $380 \quad$ (2004), https://doi.org/10.1016/j.jcis.2004.08.007

18 D. Asandei, V. Dulman, T. Todorciuc and E. Bobu, Cellulose Chem. Technol., 47, 799 (2013), http://www.cellulosechemtechnol.ro/pdf/CCT910(2013)/p.799-807.pdf

19 M. Ignat, V. Dulman and T. Onofrei, Cellulose Chem. Technol., 46, $357 \quad$ (2012), http://www.cellulosechemtechnol.ro/pdf/CCT56(2012)/p.357-367.pdf

20 S. Karmaker, A. J. Nag and T. K. Saha, Cellulose Chem. Technol., 53, $373 \quad$ (2019), https://doi.org/10.35812/CelluloseChemTechnol.2019. 53.38

21 F. A. López, A. L. R. Merce, F. J. Alguacil and A. López-Delgado, J. Therm. Anal. Calorim., 91, 633 (2008), https://doi.org/10.1007/s10973-007-8321

22 T. Wanjun, W. Cunxin and C. Donghua, Polym. Degrad. Stabil., $\quad \mathbf{8 7}, \quad 389 \quad$ (2005), https://doi.org/10.1016/j.polymdegradstab.2004.08.006 23 D. de Britto and S. P. Campana-Filho, Thermochim. Acta, 465, $73 \quad$ (2007), https://doi.org/10.1016/j.tca.2007.09.008

24 E. S. Freeman and B. Carroll, J. Phys. Chem., 62, 394 (1958), https://doi.org/10.1021/j150562a003

25 M. M. Villar-Chavero, J. C. Dominguez, M. V. Alonso, M. Oliet and F. Rodriguez, Thermochim. Acta, 670, 18

(2018),

https://doi.org/10.1016/j.tca.2018.10.004

${ }_{26}$ V. Rizzi, A. Longo, T. Placido, P. Fini, J. Gubitosa et al., J. Appl. Polym. Sci., 135, 45945 (2018), https://doi.org/10.1002/app.45945

27 C. S. Oliveira and C. Airoldi, Carbohyd. Polym., 102 38

(2014), 


\section{VIORICA DULMAN et al.}

28 M. Wawrzkiewicz and Z. Hubicki, J. Hazard. Mater., $\quad$ 172, $\quad 868 \quad$ (2009), https://doi.org/10.1016/j.jhazmat.2009.07.069

29 I. D. Rattee, Sci. Progress (1933-), 52, 581 (1964), https://www.jstor.org/stable/43426684

30 C. Zhijiang, X. Ping, Z. Cong, Z. Tingting, G. Jie et al., Cellulose, 25, $5123 \quad$ (2018), https://doi.org/10.1007/s10570-018-1914-0

31 K. Azlan, W. N. W. Saime and L. A. I Liew, J. Environ. Sci., 21, $296 \quad$ (2009), https://doi.org/10.1016/S1001-0742(08)62267-6

32 B. L. Brasol, in "The Theory of Coloration of Textiles", edited by C. L. Bird and W. S. Boston, Bradford, Dyers Company Publications Trust, 1975, https://trove.nla.gov.au/version/45637954

33 T. M. Budnyak, I. V. Pylypchuk, V. A. Tertykh, E. S. Yanovska and D. Kolodynska, Nanoscale Res. Lett., 10, 87 (2015), https://doi.org/10.1186/s11671-0140722-1

34 A. Zabulica, M. Balan, D. Belei, M. Sava, B. C. Simionescu et al., Dyes Pigments, 96, 686 (2013), https://doi.org/10.1016/j.dyepig.2012.11.001

35 H. L. Vasconcelos, E. Guibal, R. Laus, L. Vitali and V. T. Fávere, Mater. Sci. Eng., 29, 613 (2009), https://doi.org/10.1016/j.msec.2008.10.022 